\title{
Ida y vuelta. Influencia exterior en la arquitectura española (en la modernidad, y algunas consecuencias)
}

\author{
Round-trip. External influence on the \\ Spanish architecture (in modernity, and some consequences)
}

\section{Resumen}

José Antonio Sosa Díaz * admin@alonso-sosa.com Evelyn Alonso Rohner ** ear.saal@gmail.com

* Universidad de las Palmas ** Investigadora Independiente

*España

Recibido:20/Oct/2018 Aceptado: 12/Mar/2019

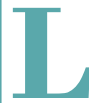

a arquitectura moderna en España pasó de ser netamente receptora en sus inicios, a ser finalmente exportadora de ideas y formas. Los primeros modernos empezaron estudiando las fórmulas y programas desarrollados en el exterior, aun cuando para poder construirlas tuvieron que recurrir al uso de las tecnologías tradicionales. Ello conllevó una aportación interesante: la del ingenio y desparpajo en la utilización de lo local. Durante la segunda modernidad, este asunto se acentuó. La arquitectura internacional de esos años incorporó materiales industriales aun inexistentes en la España de postguerra. El proceso se repite: a más innovación mayor inventiva; hasta el punto de avanzarse en formas auténticamente innovadoras. Solo al final del periodo autárquico, se produce un cambio importante, incorporándose conceptos y pensamientos vinculados al proyecto arquitectónico. A través de este recorrido histórico, se analiza la evolución de cambios conceptuales determinantes para la arquitectura que vendría después.

Palabras clave: arquitectura moderna, España, influencias externas, inventiva.

\section{Abstract:}

Modern architecture in Spain went from being purely recipient of ideas, becoming an exporter of ideas and forms. The first modern Architects began studying the formulas and programs developed abroad, nonetheless in order to build them they had to use traditional techniques. This entailed an interesting contribution: the ingeniousness and self-confidence in the use of the local techniques. During the second modernity, this issue was even more accentuated. The international architecture incorporated industrial materials that did not exist in post-war Spain. The process repeats itself: the more innovation, the more inventiveness; to the point of moving forward in authentically innovative ways. Only at the end of the autarchic period, an important change takes place, incorporating concepts and thoughts to the architectural project. Through this historical journey, we will analyze the evolution and important conceptual changes that afterwards defined the new Spanish architecture.

Keywords: external influences, inventiveness, modern architecture, Spain. 


\section{Introducción}

Las ideas y las imágenes arquitectónicas recorren hoy el mundo con absoluta permeabilidad e instantaneidad y lo hacen en todos los sentidos, de ida y de vuelta. Sobre todo, las imágenes.

Pero esto no siempre fue así. Y menos en países aislados por razones geográficas o por coyunturas políticas. La arquitectura moderna española fue en sus inicios netamente receptora de las tendencias formales surgidas en Centro-Europa. La información fundamental llegaba a través de los viajes de estudio y de las revistas. Pero al mismo tiempo, los arquitectos tuvieron que recurrir a una dosis importante de inventiva e ingenio para adecuar las técnicas tradicionales (únicas existentes en la España de entreguerras) a las formas arquitectónicas de referencia. Llama la atención, por citar solo un ejemplo, la relativa soltura y desde luego corrección, de muchos proyectos cuya esencia debía estar en la planta libre pero que paradójicamente se construyen con paredes de carga.

Durante la segunda modernidad, tras la Guerra Mundial, la arquitectura internacional incorporó materiales y técnicas de mayor complejidad industrial. Especialmente en los EEUU, se alcanzaron cotas de industrialización e incorporación de estos materiales al proyecto, impensables en la España de aquel momento: un país que seguiría arrastrando el retraso tecnológico, al menos hasta la década de los sesenta.

Ante este mayor requerimiento técnico, la capacidad adaptativa de los arquitectos españoles tampoco se vio mermada, sino todo lo contrario Su respuesta fue la misma, tratar de resolver la coyuntura técnica con elevadas dosis de inventiva y adaptación, reproduciendo celosías, carpinterías, texturas de fachada, estructuras metálicas..

Es a partir de finales de los cincuenta cuando se produce el inicio del cambio de esa tendencia. La nueva generación de arquitectos surgida tras la guerra, establece vínculos incipientes con artistas y pensadores, inicia un fructífero camino de incorporaciones ya no solo formales sino de mayor calado conceptual. Surge cierta reinterpretación de los elementos tradicionales especialmente mediterráneos (persianas, patios, terrazas), como también la incorporación intencionada de sistemas constructivos tradicionales (bóvedas catalanas, aparejos texturados de ladrillo), como también, incursiones en el campo de lo artístico, con interesantes vinculaciones con grupos emergentes (El Paso, Dau al Set...)

Aquella generación abrió el camino a que, iniciado el periodo democrático (1975), se produjese un cambio radical, invirtiendo el sentido único importador. A partir de entonces los arquitectos se unen activamente al debate intelectual europeo e internacional, sintonizando ya no solo en lo formal, sino también en el interés por las ideas, tratando de ahondar y hacer visible el vínculo entre el proyecto arquitectónico y el pensamiento que le es coetáneo.

El texto trata de exponer la relación entre la arquitectura proyectada y construida y sus orígenes, ya sean estos formales -como al inicioo los más conceptuales y profundos como al final. Mediante la vía del ensayo, se pretende alcanzar mayor libertad para expresar el testimonio, no solo de los hechos más relevantes, sino también y más fundamentalmente, de las contingentes relaciones entre formas e ideas.

\section{La modernidad, ¿como búsqueda o como estilo?} (1925-37)

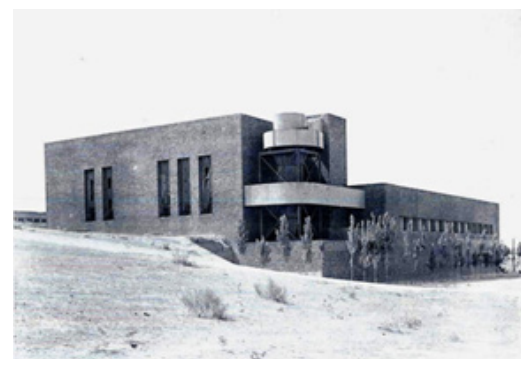

Figura 1: Manuel Sánchez Arcas y Eduardo Torroja. Central Térmica de la Universidad Complutense de Madrid. 1932

Fuente: El Poder de la Palabra (http://www.epdlp.com/ espanac.php?provincia $=($ Madrid $)$ )

Ya desde los años veinte se pone en evidencia por parte de la intelectualidad española, una notable admiración general por la técnica y el desarrollo industrial de Norteamérica. La dictadura de Primo de Rivera, en su ambigua relación con los EEUU, presentía que aquél podía ser un modelo posible, diferente al más cercano europeo, para la necesaria "modernización" de España. Esta apuesta del poder central justificó que varios Ministerios de aquel periodo comisionaran a arquitectos para que viajaran a EEUU al efecto de estudiar e incorporar nuevas tipologías y técnicas a encargos oficiales complejos. La arquitectura americana inspiró la conformación inicial de la Complutense de Madrid y algunos de sus edificios. La misma influencia se encuentra en algunos ejemplos de la arquitectura hospitalaria del momento. López Otero, Casares, Manuel Sánchez Arcas, Luis Lacasa, Muguruza y otros viajaron comisionados a EEUU desde 1927, trayendo de allí nuevas ideas y formas (San Antonio Gómez, 2006). No se trató de viajes casuales. Obedecían a un posicionamiento de cierto rechazo a las ideas 
centro-europeas y en favor de las norteamericanas Posicionamiento que llegó incluso a tomar interesantes tintes de batalla ideológica arquitectónica. Luis Lacasa, por ejemplo, rechazó explícitamente la "estética de la modernidad europea" defendiendo por el contrario "obras arquitectónicas que no tratan de desarrollar ninguna fórmula estética concebida a priori. Su finalidad parece ser simplemente la de dar forma a nuevos programas" (Cortés, 1995, p.16).

Es probable que esta múltiple conexión con EEUU, sustentada en los viajes comisionados durante ese periodo, sirva para entender el modo menos "ortodoxo" de parte de la modernidad en España. Y puede que su influencia marcara definitivamente el entendimiento múltiple de la arquitectura moderna, desde una óptica más compleja e inclusiva, en la que caben desde los posicionamientos más matéricos y estructurales, hasta los más abstractos y livianos del rigor centroeuropeo.

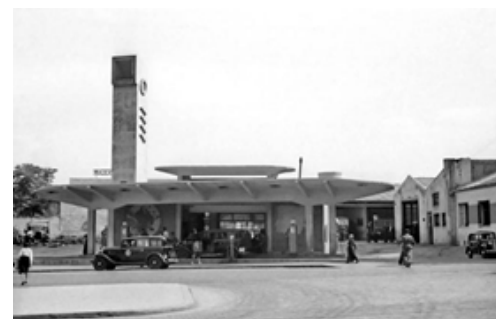

Figura 2: Casto Fernández-Shaw. Gasolinera Porto Pi. Madrid. 1927

Fuente: Del libro 'Madrid a pie de calle' del reportero gráfico Manuel Urech.

El debate, bien fundado e inteligente, sustentado por Antón Capitel, Juan Antonio Cortés y Carlos Sambricio sobre el mayor o menor peso de esta línea "americana", reafirma la idea de que esta arquitectura de encargo oficial fue importante para entender esa "otra modernidad" que encontró profunda raíz en algunas áreas de la producción arquitectónica española.

La realidad es que la variedad formal de la arquitectura española de la primera modernidad no resiste una asignación regional a pesar de los debates surgidos en diversos momentos, aunque estos hayan sido con frecuencia defendidos por grandes investigadores.

Aquella arquitectura de tintes americanos, convivió en Madrid, por nombrar una de las geografías más estudiadas, con apuestas más híbridas, como las de Casto Fernández Shaw, Secundino Zuazo, Torrojas y Arniches, o incluso muy "puristas", y de mayor influencia centroeuropea, como las de Bergamín y Blanco Soler en la Colonia el Viso.

La realidad es que no fue este un asunto de regiones, sino una toma de posición por parte de arquitectos individuales. Dentro de cualquier ámbito geográfico, fueron más las excepciones que las reglas a un patrón común. Quizás tuvo que ver con la ausencia, en aquellos momentos iniciales, de un maestro fuerte, capaz de crear escuela y tendencia y, en consecuencia, con la mirada limitada e individual hacia referencias del mundo exterior.

La presencia de José Manuel Aizpurúa y Joaquín Labayen en el País Vasco, Gutiérrez Soto o Rafael Bergamín en Madrid, Sixto Illescas o José Luis Sert en Barcelona, Miguel Martin-Fernández o Blasco en Canarias, es suficiente para acreditar la coexistencia de una línea "ortodoxa" de gesto radical y centro-europea, de calidad relevante antes y durante la llegada de la Segunda República. La influencia de estos arquitectos provino especialmente de sus viajes a Europa y por supuesto de los libros y especialmente revistas extranjeras.

Los viajes fueron en su mayoría privados, pero también los hubo "oficiales", como los ya citados a EEUU, o los de Mercadal y Zavala, y luego Sert, Torres Clavé, Ribas y Bonet a los CIAM, así como alguna colaboración en estudios internacionales, como las de Sert con Le Corbusier. Fueron trascendentes en aquellos momentos iniciales, las aportaciones producidas por las conferencias impartidas en España entre 1928 y 1930 y en especial, las cuatro de la Residencia de Estudiantes: Le Corbusier (1928), Erich Mendelsohn (1929), Gropius (1930) y Van Doesburg (1930).

En relación con la información recibida a través de las publicaciones en aquellos primeros años, basta un análisis de las bibliotecas de aquellos arquitectos para descubrir con asombro lo "al día" que se encontraban algunos de los más destacados, tanto como la calidad extraordinaria de las revistas de aquel momento. La biblioteca de Miguel Martin-Fernández, sirve como ejemplo de constatación. Manuel Martín Hernández la define de este modo:

Es excelente la selección de revistas de arquitectura en el estudio de Miguel Martín, lo que permite asegurar una rigurosa puesta al día a partir de la acumulación de información sobre las vanguardias arquitectónicas durante las décadas de los veinte y los treinta en Europa. Las colecciones de "Monatshefte für Baukunst", desde 1920, editada por Wasmuths (de la que habría que destacar el número monográfico 1/2. 1924 dedicado a Mendelsohn o el trabajo de A. Behne sobre la arquitectura holandesa en el 1/2. 1921) o la de "Moderne Bauforme" (que publica selecciones de arquitectura moderna hechas por L. Hilberseimer -9 . 1927-, H. Häring -9. 1928- o B. Taut sobre la arquitectura soviética- 2.1930-), permitirán entender la evolución de las nuevas propuestas desde unos de sus focos.

Aun cuando solo está un número de 1928 y los de 1929 y 1930 de "L’Architecture vivante", dirigida por J. Badovici, aparece casi toda la producción racionalista de Le Corbusier y P. Jeanneret hasta esa fecha y los monográficos dedicados a F.LI. Wright-28. 1930), la arquitectura holandesa-21. 1928- y la de la URSS-29/30. 1930. Entre los números sueltos de la revista "Wendingen", órgano propagandístico de aquel grupo holandés, están los dedicados a W.M. Dukok en 1928 y 1930 y el monográfico de la Fábrica Van Nelle-2.1930. (MartínFernández, 1987, pp. 37-38)

Relevante en la difusión de la técnica y el espíritu de la modernidad, tanto a los jóvenes alumnos de la Escuela de Madrid del momento, como a sus profesores, fue el Donativo Cebrián a la Biblioteca de la Escuela, constituido por un amplio fondo bibliográfico del periodo 1903 
1932 conformado por publicaciones procedentes tanto de EEUU (donde Cebrián desarrolló su vida profesional) como de Europa.

Llegada la Republica al poder (abril de 1931), a este nivel de información exterior se va a sumar una nueva iniciativa de voluntad vanguardista, ánimo propagandista - y lo que es más importante - intención de superación del voluntarismo individual. Se forman y apoyan grupos de acción, especialmente en torno a las revistas, que tratan de modificar el panorama atomizado ya descrito, transformándose en aglutinadores y creadores de opinión. Entre ellas, destaca AC del GATEPAC, pero también Gaceta de Arte en Canarias, ambas aglutinadoras de artistas y arquitectos de la época. Ambas nacen con tan solo un año de diferencia (1931 y 1932 respectivamente) y obedecen a parámetros similares en su fin y en su presentación.

La revista AC parece afianzar la modernidad en España de una manera "oficial" y definitiva. El primer número publica algunos de los ejemplos arquitectónicos recogidos en la "Exposición de Arquitectura y Pintura Moderna de San Sebastián" organizada en 1930 por el Ateneo Guipuzcoano. Precisamente esta exposición había sido acicate para el inicio y fundación del Grupo de Arquitectos y Técnicos Españoles para el Progreso de la Arquitectura Contemporánea (GATEPAC). Los tres proyectos que aparecen en sus primeras páginas (que dicho sea de paso descartan los ejemplos de modernidad "moderada") señalan una línea clara de pureza moderna: la Casa Vilaró de Sixto Illescas, el proyecto de Escuelas Elementales de Ibarra y la Pastelería y Salón de Degustación "Sacha" ambos de Aizpurúa y Labayen. De algún modo destacaban una tendencia más depurada del racionalismo, vinculada a las geografías más participativas en esas publicaciones. En el campo del urbanismo, señalar la importancia del Plan Maciá, elaborado en colaboración entre los componentes de GATPAC, con la participación activa de Le Corbusier y Pierre Jeanneret (invitados por Sert en 1932).

Es destacable por su influencia en la arquitectura moderna española posterior, el número 6 de AC, que destacaba - alentado especialmente por Sert - la aceptación de los principios de la arquitectura mediterránea tradicional, definiéndola como un posible ejemplo propositivo hacia una nueva modernidad española, con diferenciación

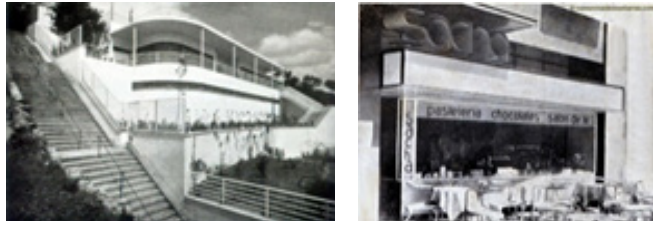

Figuras 3 y 4: A la izquierda: Sixte Illescas. Casa en Vilaró Barcelona. 1929. A la derecha Aizpúrua y Labayen. Pastelería y salón de degustación Sacha. San Sebastián 1930.

Fuente: https://www.urbipedia.org/hoja/Casa_Vilaró y Comercios Donostiarras. climático-geográfica. Hablando de la arquitectura tradicional ibicenca, se sostiene aquí cierto principio de "latinidad" a través de la aceptación de la pureza formal de los volúmenes, la definición de las sombras y persianas, y el descubrimiento de una arquitectura cuas perfecta, "que no necesita renovación". Esta propuesta de "contaminación" aceptable de la ortodoxia europea desde la aplastante lógica del clima y de los materiales, se conformará luego como indiscutible diferenciador de la mejor arquitectura moderna catalana y balear.

\section{Inventiva frente a escasez y cerrazón (1940-57)}

La época que a uno le toca vivir determina normalmente el desarrollo de su propia actuación. Compartir un mismo interés, participar activamente de una evolución colectiva teniendo la libertad suficiente para unas veces adelantarse a ella y otras ir rezagado, pero mantenerse siempre en el tren de la época, es la oportunidad, y también la grandeza, de quienes viven en su tiempo.

El rol de la arquitectura española a partir de la Guerra Civil no escapa de esta realidad; cambian, y mucho, las circunstancias, pero no tanto esta pauta. La dura adversidad, las especiales características españolas de mediados del siglo XX, no ponen sino en evidencia la capacidad que tuvieron algunos arquitectos para actuar como sismógrafos, en extremo sensibles, capaces de detectar de nuevo los epicentros norte-europeos o americanos donde se mantenía activa la modernidad.

Tras la Guerra, y en el plano cultural, España estaba muy condicionada por el régimen político y sus gustos retrógrados, a los que se suma el inevitable aislamiento cultural. Esto obliga a los arquitectos de aquel momento (a aquellos que no tiraron la toalla o tuvieron que emigrar) a un especial esfuerzo por mirar hacia el exterior, asomándose a la ventana de las revistas y viajando. ${ }^{1}$

La involución del país, especialmente en estos primeros años, fuerza la desconexión respecto a lo que sucede fuera, $y$, sobre todo, dificulta la creación de grupos de acción o de vanguardia como los anteriores, que pudieran definir su clara pertenencia o adscripción a una forma moderna de entender la arquitectura.

\subsection{La herencia del periodo heroico y la ruptura generacional}

Sobre la geografía destruida del país pervivía parte de la arquitectura moderna realizada antes de la Guerra.

${ }^{1}$ Como los de Francisco de Asís Cabrero a Roma, en 1941, Sáenz de Oíza a los EEUU (1947-1948) o ya más tardío, la relación con e Team X de Jose Antonio Coderch, y su asistencia al Congreso de Otterlo en 1959, por citar solo algunos. Una información exhaustiva al respecto, es recogida en las actas del congreso internacional "Viajes en la Transición de la Arquitectura Española hacia la Modernidad" Celebrado en Pamplona los días 6 y 7 de mayo de 2010 en la ETSAUN. 
Sin embargo, al contrario de lo que pudiera suponerse, ya sea por ruptura generacional o por conexión con la producción exterior (más probablemente lo primero), no se aprecia una continuidad entre aquella primera modernidad del periodo heroico y la que se construye durante la penuria de postguerra a finales de los cuarenta. A veces se comete el error de tratar de englobar lo sucedido en todo el país bajo un único parámetro, cuando en realidad las circunstancias van a ser muy diferentes en función de las regiones. La obstinación por parte del poder autárquico por bloquear lo que venía de fuera la compartieron todas, pero era variada la voluntad y la capacidad de relación con el exterior que poseían las diferentes regiones del país, así como era diferente el alcance del control político existente en el centro y en la periferia.

Aunque en general, hasta finales de la década de los cuarenta no llegaron de nuevo revistas del exterior, había regiones mejor conectadas en las que la información fluía mejor. Era el caso de Cataluña por su proximidad con la frontera y por su tradición arquitectónica moderna. ${ }^{2}$

En general, ante la falta de un proyecto colectivo y fuerte, como el que llegaría en los 60, las diferentes actitudes, compromisos y cultura trazan caminos personales y diferenciados. Las escuelas de procedencia señalan diferencias, pero quizás no tanto como para dividir arquitectónicamente el país en dos bloques, a pesar de lo que se ha afirmado en ese sentido: Entre José María Sostres, Miguel Martin-Fernández, Fernando Cavestany, Bar Boo, Moreno Barberá o Fisac, por citar una contingente muestra de geografía arquitectónica de la época, existe un componente personal más fuerte y diferenciador que lo de común puedan tener por su simple adscripción académica. Eso sin olvidar los arquitectos que tuvieron que emigrar del país para trabajar fuera (Bonet Castellana, Sert, Candela...) y lograron construir sus proyectos en el exterior, con lógica influencia sobre sus coetáneos.

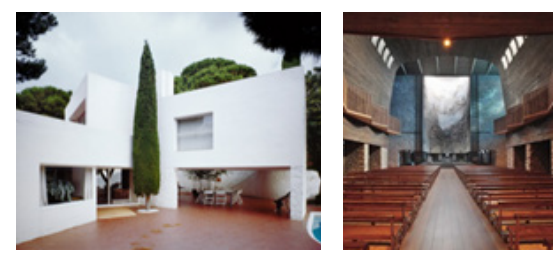

Figuras 5 y 6: A la izquierda: José Antonio Coderch. Casa Ugalde. Caldetas. 1952. A la derecha Oiza y Laorga. Basílica de Aránzazu en Oñate. Guipúzcoa. 1950-1955.

Fuente: Horma estudio http://hormaestudio.com/ portfolio_page/jose-antonio-coderch/ y Registro DOCOMOMO ibérico.

Otra de las características de ese periodo de postguerra es la escasez y la consecuente carencia de materiales, muy limitados por la ausencia de alternativas técnicas y materiales locales innovadores, así como por los exiguos cupos de importación. Surge así la necesidad de aplicar uno de los principios de la modernidad más elemental y desprejuiciada, la de tener que reinventarse. Cuestión en la que pocos superan a España es en la capacidad inventiva. No la del genio que crea nuevos productos, pero sí la del que vive en la subsistencia, enfrentado a la inevitable y continuada escasez de recursos, es decir, la del ingenio. A través de esta capacidad, los arquitectos recurren a los materiales artesanales y tradicionales, pero dotándolos de nuevos sentidos y formas, recuperando, por ejemplo, las bóvedas tabicadas, los ladrillos vistos, las carpinterías y persianas de madera, los pavimentos de barro cocido, o el empleo de celosías palomeras... para con ellos, desarrollar interesantes investigaciones que, tratando de mantener los principios formales de la arquitectura exterior, confieren a la nacional, tanta diferenciación constructiva, que generan en su construcción real proyectos dotados de un nuevo sentido.

Hasta finales de los cincuenta, los dos condicionantes citados (escasez y cerrazón) obligaron a la arquitectura española a inventar y adaptar las soluciones a los medios disponibles, desarrollando nuevas formas desde viejos materiales, pero también dando respuestas inteligentes a programas de absurda rigidez y jerarquías imaginadas por el poder. Pero, ¿acaso no es la capacidad para inventar y redefinirse justamente la definición de lo moderno? Ninguna definición mejor que la de Octavio Paz:

En la modernidad, nada hay nuevo bajo el sol, excepto las creaciones e inventos del hombre; nada es nuevo sobre la tierra, excepto el hombre que cambia cada día. Aquello que distingue al instante de los otros instantes es su carga de futuro desconocido. No repetición sino inauguración, ruptura y no continuidad (Paz, 1966, p. 5).

\section{Al fin, acompañados (1957-68)}

1957 es el año en que llega el reconocimiento internacional y la divulgación exterior de la arquitectura española y lo hace a través de una joven generación premiada en las exposiciones internacionales de la XI Trienal de Milán (Carvajal y García de Paredes) y Bruselas (Corrales y Molezún). La presencia de estos arquitectos en ambas exposiciones evidencia una clara voluntad política de externalización y propaganda que también encuentra reflejo en el manifiesto del grupo el Paso y la presencia de la pintura abstracta española en los propios

${ }^{2}$ Las conferencias en 1949 en la V Asamblea Nacional de Arquitectos en Barcelona, de Alberto Sartoris (de influencia en Canarias a través de su amistad con Westerdhal), Gio Ponti (Domus) y Bruno Zevi fueron decisivas para el "descubrimiento" y valoración, por foráneos, de lo que en aquel momento se hacía en España, destacando especialmente la relevante primera obra de José Antonio Coderch y Manuel Valls (casa Garriga Nogués, Sitges,1947). Estas conferencias impulsaron la creación del grupo $\mathrm{R}$ en Cataluña (Luis Domenech). Ver Cortés, J. A (2001): Internacionalismo y Referencias vernáculas en los años cincuenta. Madrid, España: Tanais. 
pabellones internacionales. Esta externalización señala un cambio de rumbo, hacia la anhelada apertura a otros horizontes.
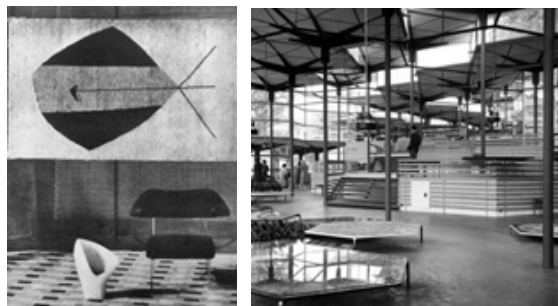

Figuras 7 y 8: A la izquierda: Javier Carvajal y García de Paredes. Pabellón de España. Primer premio en la X Trienal de Milán. A derecha: Corrales y Molezún. Pabellón de España. Medalla de Oro. 1958

Fuente: Flores, C. (1961): Arquitectura española contemporánea, Bilbao, España: Aguilar, p. 383, y Reginald Hugo de Burgh Galwey (1917-1971).

Fuera de España se produce un momento de cambio profundo en las corrientes y el pensamiento arquitectónico internacional. Es tiempo de reformulaciones: del nuevo pensamiento urbanístico del TEAM X, de los nuevos materiales, de la aplicación de la industria bélica a la construcción civil en EEUU y de su decisiva influencia en las nuevas formas...pero también, de los fotógrafos y de la divulgación masiva de la arquitectura, de los cambios conceptuales en las artes (especialmente a mediados de los años sesenta) y su relación con nuevos posicionamientos. Para España es tiempo, de volver la mirada hacia el exterior geográfico, pero también, y en eso coincidimos con el resto, de mirar hacia el exterior de la disciplina.

Como antes, la respuesta no fue homogénea en e país. Aunque los ejemplos de conexión exterior fueron suficientes como para señalar una época y formar un grupo de profesionales con capacidad de marcar decididamente a las siguientes generaciones.

Antón Capitel, refiriéndose al inicio del periodo 1957 sostiene:

El triunfo del Estilo Internacional era así culturalmente definitivo, pero este se presentaba...según tres clases generales de interpretación: las versiones radicales y tardo-primitivas, en las que los proyectistas se mimetizaban en parte con los pioneros de la arquitectura moderna (Sáenz de Oíza, De la Sota, Cabrero), las versiones desarrolladas más de acuerdo con el momento cultural en el exterior (Coderch, De la Hoz y García de Paredes), o las que ya incluían algunas consideraciones e indicios de revisión (Fisac, y algunas obras menores de La Sota o de La Hoz y García de Paredes). (1995, p. 406)

\subsection{Reformulación del pensamiento: la importancia del lugar y el reenfoque de la ciudad}

Para aquellos arquitectos que alcanzaron a participar de las ideas del momento se trataba de un nuevo comienzo. De hecho, algunos de los conceptos que nos interesan hoy, nacen precisamente en aquellos años. No tanto, y esto es lo importante, en lo que afecta a la epidermis y a la forma, sino en los conceptos que sustentan la producción de esas formas.

A partir de ahora, la nueva modernidad, presta más atención a la relación con el entorno, ya sea este la trama urbana o los paisajes del contexto. En esos años se inicia un ligero desplazamiento (que consolidará en los ochenta) que empuja el inicial interés del periodo heroico por el objeto arquitectónico (con valor en si mismo) hacia la proposición y capacidad que este mismo objeto tiene para generar nuevos lugares o, utilizando las ideas de Alison Smithson, para construir ambientes. Desde nuestra sensibilidad actual, inmersos en una producción arquitectónica de mirada señaladamente atenta al lugar, destaca el giro tomado entonces por la arquitectura y la creciente atención a los problemas de inserción urbanística y más tarde, medioambiental y paisajística. Tanto como la nueva abertura e interés hacia lo extradisciplinar, a la sociología y al arte, a la estructura y la forma...

Es el momento también de la formulación del urbanismo unitario, de la atención a una relación más intensa entre arquitectura y ciudad y la concepción integradora de las funciones urbanas (TEAM X). Pocos son los arquitectos españoles que tuvieron la oportunidad de participar directamente en la concepción de aquellas ideas foráneas, como José Antonio Coderch, pero el panorama cambió al lograr engancharse la vanguardia española al tren europeo. Podría decirse que, en ese momento, la arquitectura española ya superaba el axioma del vaciamiento conceptual advertido por Carlos Flores, para situarse, por primera vez, en conexión directa no ya con las formas, sino con los conceptos que les dan vida.

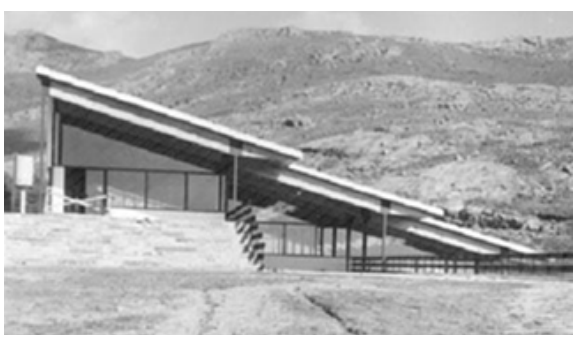

Figura 9: Alejandro de la Sota, Corrales y Molezún. Residencia en Miraflores de la Sierra. Madrid. 1957 Fuente: http://www.lacristalera.com/2011/08/25/origenes/

\subsection{Nuevas respuestas a nuevos retos}

Ante los cambios de pensamiento que surcan los años sesenta y que culminan en la revolución ideológica de finales de la década, se replantea también la del principio organizativo del proyecto, tradicionalmente dado por válido y encerrado en la estructura compositiva. La relación entre programa y forma se había sustentado, a lo largo del tiempo, en la consolidación de tipos edificatorios más o menos permanentes, basados en estructuras 
organizativas socialmente estables. Aunque la fijación de binomio forma-función fue una de las premisas iniciales del Movimiento Moderno, la efectiva puesta en marcha de la investigación de nuevos sistemas organizativos se produce básicamente al llegar estos años. Los métodos de diseño e información defendidos y puestos entonces en práctica por Christopher Alexander (A city is not a tree, 1965) y luego Nuno Portas, definen una nueva forma de organización espacial más apoyada en la fragmentación y adición que en la composición global y unitaria anterior.

La unidad formal se sustenta ahora en un armazón compositivo capaz de recibir, conectar o enchufar en él las distintas funciones en torno a unas infraestructuras básicas de intercomunicación. Las propuestas metabólicas de Tange en Japón o de Van der Broek y Bakema en Holanda, construidas bajo ópticas formalmente divergentes, coinciden, sin embargo, en el método de trabajo y en la concepción estructuralista de la composición. Ello lleva a que el sentido de unidad global pierda fuerza frente al de complejidad aditiva, iniciándose así también en aquellos años otra vía que llegará reforzada hasta nuestros días: la de la generación de nuevas formas ante nuevos programas; la reformulación de lo conocido y la investigación en el campo organizativo y programático del edificio. Aunque en España estos cambios conceptuales no fueron tan marcadamente obvios, determinaron una nueva manera de entender la composición, más abierta y contingente. Es el caso de Rafael Leoz que a través del módulo Hele, replantea una organización agregativa y modular en el campo de la vivienda o, también dentro de principios estructuralistas, algunas propuestas de composición abierta, como el Hotel Oasis (1965) de Corrales y Molezún con De la Peña en Gran Canaria, cuya conformación a base de cuerpos entretejidos y patios intercalados se vincula directamente con los mat-building del momento (Hospital de Venecia, Universidad Libre de Berlín...). As como también al uso de la superposición y yuxtaposición como principio organizativo de edificios como La Casa Del Marino (1958-1964) de Miguel Martin Fernández en Las Palmas.

\subsection{El material y las formas}

La incorporación, en los años cincuenta y sesenta, de nuevos elementos constructivos, tanto por la mejora de las condiciones industriales, como la apertura (ligera) a los mercados exteriores, amplía el estrecho abanico de materiales disponibles. Los paneles de todo tipo, combinados con el acero extrusionado, los materiales que provienen de la industria militar (maderas laminadas, chapas de aluminio) cuyas nuevas formas se recogieron en las investigaciones estructurales de Fuller o Larrabee Barnes, o en los programas "Case Study Houses" o "Design for Post-War Living", ya ampliamente publicadas en España, y las consiguientes realizaciones de los Eames, Frey o Neutra, aportan una nueva riqueza formal que se incorpora con franca rotundidad a la arquitectura española. La modulación y voluntad estandarizadora, entendida casi como principio proyectual, de Alejandro de la Sota o de Sostres, el uso expresivo de los perfiles
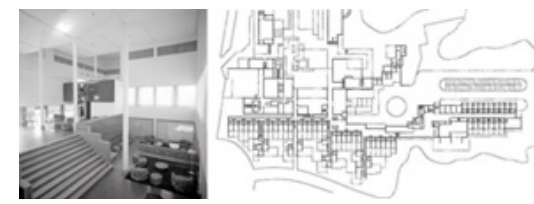

Figura 10: Corrales, Vázquez Molezún y De la Peña. Hote Oasis, Maspalomas. Gran Canaria. Primera fase: 1965 1967. Segunda fase: 1969-1971. Estructura porosa y abierta.

Fuente: Fachico Rojas, 1965, y Corrales y Molezún.
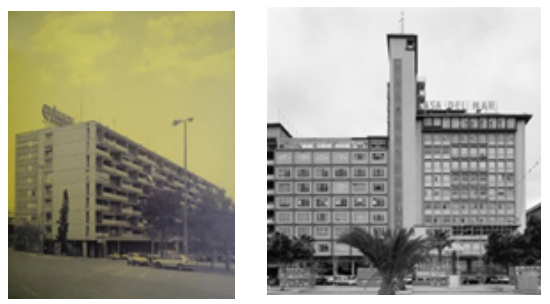

Figuras 11 y 12: a la izquierda Mitjans y Miró. Edificio de viviendas Manzana Seida. Barcelona. 1959-67. Organización de elementos superpuestos. A la derecha Miguel Martín-Fernández. Casa del Marino. Las Palmas de Gran Canaria. 1958-1964.

Fuente:www. pinterest.com/pin/328059154082015603/ y Sosa Díaz- Saavedra, J. A. (2002): Archivos de Arquitectura. España Siglo XX. Almería, España: Colegio de Arquitectos de Almería, p. 70.

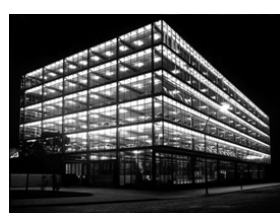

Figura 13: César Ortiz-Echagüe y Rafael Echaide. Filial de Seat. Barcelona. 1958

Fuente: Pando.

laminados en Ortiz Echagüe o en la Facultad de Derecho de Barcelona de López Iñigo, Giráldez y Subías, son buen ejemplo de la influencia de aquellas investigaciones formales norteamericanas pasadas inteligentemente por el tamiz de lo local.

Sin embargo, a pesar de la fascinación por aquel abanico de nuevos materiales, la limitada recuperación económica de finales los cincuenta, hacía aún difícil encontrar los aluminios, las chapas o los paneles de "plywood" comunes en la arquitectura de las deslumbrantes fotos de las revistas norteamericanas de la época. Así que de nuevo en este campo se echó mano de la inventiva, recurriendo al empleo de materiales disponibles, pero desde nuevas formalizaciones.

La mirada de este momento sobre el panorama internacional no va a limitarse solo a la arquitectura norteamericana, ligera y quizás más vinculada a la 


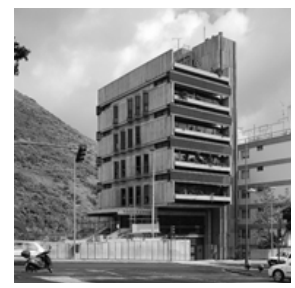

Figura 14: Javier Díaz Llanos y Vicente Saavedra. Sede COAC. Santa Cruz de Tenerife. 1966.

Fuente: Sosa Díaz-Saavedra, J. A. (2002): Arquitectura Moderna en Canarias: 1925-1965. Tenerife, España: Colegio Oficial de Arquitectos de Canarias, p. 167

escuela miesiana; también se volverá hacia la otra mitad del continente americano y se extenderá con éxito a materiales más pesados: hormigones vistos, de complejos encofrados de madera, o revestimientos cerámicos de color. En concreto a la arquitectura moderna suramericana, más vinculada al Le Corbusier de los cincuenta, de los parasoles, los brise-soleil y los hormigones vistos, y que se combina aquí con las influencias del entonces incipiente brutalismo europeo.

\subsection{La contaminación positiva: lo extradisciplinar}

Sería interesante desarrollar más extensamente un estudio que profundizara en el vínculo formal y conceptual que se produjo en aquellos años entre las formaciones artísticas de la posguerra y la arquitectura coetánea. La creación del Grupo Dau al Set (1948), de la Escuela de Altamira (1949) y, más especialmente, de Grupo El Paso (1957-1960), las mallas vibrantes de Rivera, unido a la expansión social y política que adquiere Tapies en esos años o las geometrías planas de Palazuelo, son la expresión de un nuevo pensamiento que encuentra rápida conexión e incluso adscripción entre los jóvenes arquitectos de entonces. No solo en el establecimiento de colaboraciones puntuales entre destacados artistas y arquitectos del momento, sino, sobre todo, en el fortalecimiento de un sentimiento de pertenencia y enlace cultural de la arquitectura, situada en plano de igualdad, experimental e inventiva, con el resto de las artes. Se trata de una adscripción cultural más, como la que proviene del pensamiento puro o de la materialidad, y que centra el interés y el sentido de pertenencia de determinados arquitectos a movimientos plásticos de notoria influencia en toda la producción cultural.

\subsection{Lo orgánico}

De entre las múltiples facetas que recorre la arquitectura española en los años 60 y 70, merece mención especial la arquitectura orgánica, de la que se encuentran ejemplos destacados apoyados especialmente de la influencia báltica de Alvar Aalto y de Utzön (Moneo colabora de recién titulado en su estudio). Llega avalada por los textos de Bruno Zevi (Hacia una arquitectura orgánica, 1945) y de Sigfried Gideon (Espacio, tiempo y arquitectura, 1967). ${ }^{3}$

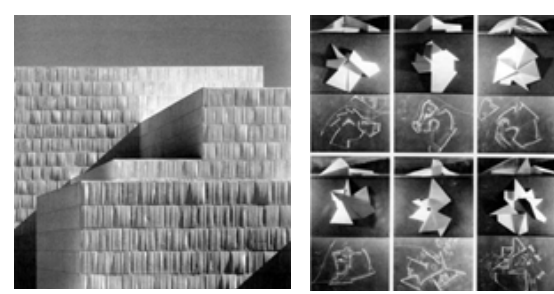

Figuras 15 y 16: a la izquierda Miguel Fisac. Centro Cultura en Castilblanco de los Arroyos. Sevilla, 2000. A la derecha Fernando Higueras. Diez residencias de artistas. 1960 Fuente: Centro Vasco de Arquitectura y https://www. friso.es/blog/tag/fernando-higueras-arquitecto/

Torres Blancas de Oiza (Madrid 1961-68), el edificio Girasol (Madrid 1964-66) o los edificios Trade (Barcelona 196568) ambos de Coderch, son exponentes de este momento orgánico español de precisas geometrías ondulantes.
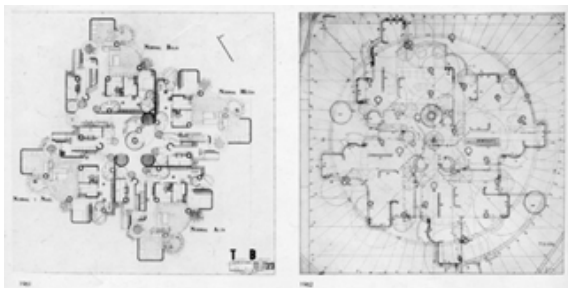

Figura 17: Fco. Javier Sáenz de Oiza (con la colaboración de Juan Daniel Fullaondo). Torres Blancas. Madrid. 1961-68. Fuente:https://lalumiereparle.wordpress.com/2014/10/19/ saenz-de-oiza/

\section{Una revolución y dos re-vueltas (1968-90)}

Ni los escritos de Reyner Banham de los sesenta, ni e Pop Ingles, ni el movimiento hippie, ni Mayo del 68 de notable influencia posterior sobre la arquitectura europea, tuvieron mucha repercusión en España. Parte de la arquitectura de vanguardia europea de aquel momento, como los Radicales italianos, de Archizoom y Superstudio entre otros, o Archigram, Coop Himmelblau, y las propuestas también audaces de Jean Louis Chaneac y su Architecture Interdite, encontró escaso eco en España con la excepción hecha de alguna experiencia aislada, pero precisamente por ello destacable. De entre ellas, las de los jóvenes Carlos Ferrater o Prada Pool. España no era muy propicia a aquellas salidas del "orden" y este flash de alucinante creatividad, vinculado con las

${ }^{3}$ La repercusión interior, decisiva en la fundamentación metodológica y conceptual de la época, descansa en gran medida en la revista Nueva Forma, desarrollada entre 1966 y 1975 en 111 números y dirigida por Juan Daniel Fullaondo. Fue su relevo cronológico, Arquitecturas Bis fundada por Orio Bohigas y dirigida por Rosa Regás con 52 números publicados durante el período de 1974 a 1985 
prácticas más lúdicas y hippies de burbujas, semiesferas y estructuras neumáticas multicolor, quedó rápidamente ahogada en la mirada adusta y de fuerte carácter disciplinar del emergente postmodernismo.

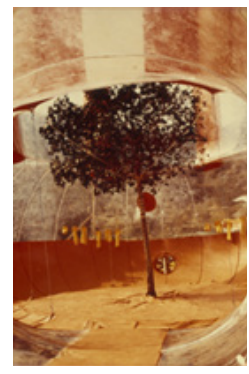

Figura 18: Instant City es una de las pocas inmersiones en aquel momento cultural fascinante. Carlos Ferrater Fernando Bendito y José Miguel Prada Poole, Ibiza 1971. Fuente: Quaderns \#262

Por qué razón se cerró esa vía de trabajo de forma tan radical no se explica solo por la difusión de los textos de Rossi y de Venturi, a pesar de su enorme influencia en las Escuelas de Arquitectura del momento. Aquel cambio rompió la trayectoria de una década de mestizajes, y positivas intoxicaciones de arte y pensamiento, que habían fecundado la arquitectura de nuevas reflexiones y formas.

Lo postmoderno enraizó bien en España. En los años precedentes se había producido, fuera de sus fronteras, una lenta pero implacable evolución e interés hacia e interior de la disciplina, con ejemplos destacados muy divulgados y estudiados en la España de la época, como algunos proyectos de Louis Kahn (Biblioteca Exeter, 1965-72), los Smithson (The Economist, 1961-64) o Peresutti y Rogers (Torre Velasca de Milán, 1957-60) por citar algunos ejemplos de alta repercusión mediática que ayudan a entender los inicios de este periodo.

Quizás no sea muy arriesgado englobar este periodo en España entre dos destacadas obras de Moneo que en su momento tuvieron gran influencia mediática: el edificio Bankinter (Moneo y Bescós) de 1969-76 y el Museo Romano de Mérida 1979-1986. La postmodernidad arquitectónica alcanza un fuerte desarrollo y pervivencia en todas las comunidades a través de una alta contención y calidad en las arquitecturas de, entre otros, César Portela, Cruz y Ortíz, Vázquez Consuegra, Linazasoro, Peña Ganchegui, el Taller de Arquitectura de Bofill, Clotet y Tusquets. Un análisis crítico (de la obra más importante) de este periodo es el realizado por Eduard Bru y José Luis Mateo a través de su decisiva aportación en Quaderns o el libro Arquitectura Española Contemporánea (1990).

En los últimos ochenta, se produce cierta exacerbación y posterior remate del postmodernismo internacional bajo la influencia externa de los hermanos Krier, del influyente texto de Charles Jencks (The Language of Post-Modern Architecture, 1977, en España, 1980), o de la posterior

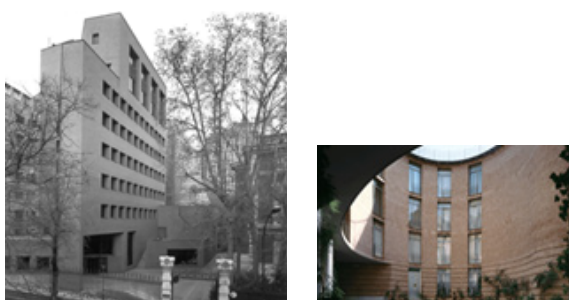

Figuras 19 y 20: a la izquierda Rafael Moneo y Ramón Bescós. Edificio Bankinter, Paseo de Castellana, Madrid, 1969-1976. A la derecha Cruz y Ortiz. Viviendas en la calle María Coronel. Sevilla, 1973-76.

Fuente: Tres proyectos, tres décadas: La arquitectura de Rafael Moneo y Cruz y Ortíz Arquitectos.

puesta en escena y apoteosis del IBA de Berlín de 1987 (Joseph P. Kleihues). Esta traca final ensombrece el panorama de muchos suburbios españoles conformados por un urbanismo comercial aburrido y estéril, justamente desarrollado en el momento de mayor expansión inmobiliaria. Afortunadamente, también aqu hubo excepciones, como las inteligentes estrategias de Oriol Bohigas para la reordenación de Barcelona (198092) o los reveladores textos e investigaciones de Solá Morales o Manuel Castells, defendiendo posiciones menos disciplinares y al mismo tiempo, más abiertas a realidades de mayor complejidad social

El derrotero a partir de esos años se hace tan variado, que cualquier intento por racionalizar lo que ocurre se pierde en una imposible clasificación de "corrientes" y adscripciones. En adelante la lectura del panorama arquitectónico ya no será más la de un estilo dominante, sino la de convivencias múltiples. Más que una línea o una corriente, lo que se percibe es una topografía de complejo paisaje donde cohabitan, en distintas combinaciones, los pensamientos y las formas.

\subsection{La pervivencia de la modernidad ortodoxa y el espacio compartido con las otras artes}

Durante este periodo pervivió cierta modernidad no carente de ortodoxia, que en gran medida se apoyó en el referente del desaliño formal pero de piel tersa de Alejandro de la Sota. Su fidelidad a la modernidad, aun en el contexto más radical de la postmodernidad, sirvió de acicate a los que no quisieron abdicar y continuaron con una línea de trabajo muy atractiva y de gran proyección fuera de España como la de Piñón y Viaplana, Elías Torres y Lapeña, Josep Llinás, José Luis Mateo, Vázquez Consuegra, Virgilio Gutiérrez... para más adelante desarrollarse en la sencillez atractiva de la arquitectura de Alberto Campo Baeza, Elisa Valero o José Antonio Ramos e Ignacio Vicens solo por citar algunos.

No menos importante, para entender el siguiente apartado fue el reconocimiento y la recuperación de un espacio común entre el arte y la arquitectura. A partir de ahora los conceptos manejados en arquitectura, además 

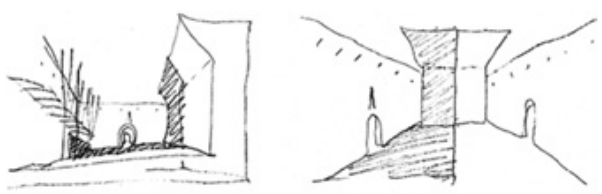

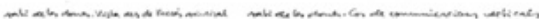

Figura 21: Helio Piñón y Albert Viaplana. Centro de Cultura Contemporánea de Barcelona, 1990-94 Fuente: https://cajondearquitecto.com/2013/06/24/ alzado-cccb/
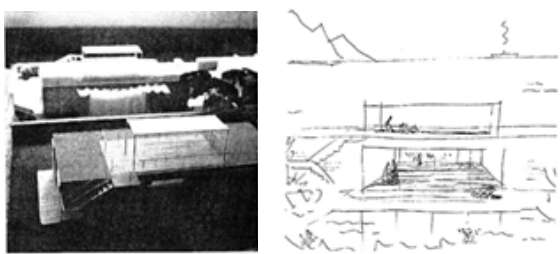

Figura 22 y 23: Alejandro de la Sota, Alcudia, 1984 Fuente: Fundación Alejandro de la Sota.

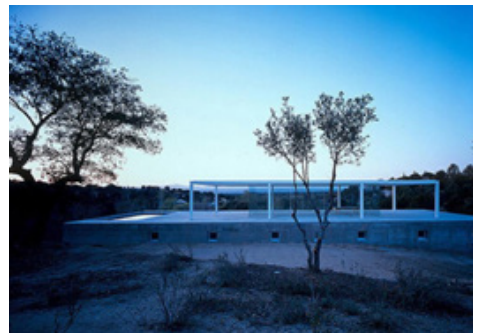

Figura 24: Alberto Campo Baeza. Casa de Blas, 2000 Fuente: Hisao Suzuki.

del pensamiento social y filosófico, se relacionan también con los propios de la producción artística. La relación con la creación en otros campos disciplinares es un modo de detección sensible del pensamiento contemporáneo. Quizás más que nunca, arte y arquitectura comparten un campo común; se establece una relación que no es de préstamo (inserción de obras en el interior de la arquitectura) sino de apoyo en cimientos comunes. El arte conceptual, el povera, el land-art, el minimal, ... y todos los movimientos nacidos en los sesenta, aún vigentes, influyen decididamente en aquel momento. También lo hace el compartir una visión sensible y un posicionamiento creativo común. La arquitectura mira ahora hacia otros campos; hacia el exterior de la disciplina con la sensibilidad del artista, detectando posicionamientos culturales y ordenes de pensamiento. No se trata solo de integrar las artes plásticas a la obra arquitectónica sino de compartir una mirada común.

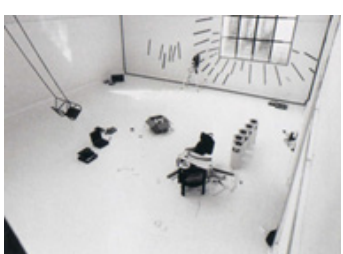

Figura 25: Juan Navarro Baldeweg. "Luz y Metales" en la Sala Viçon, Barcelona, 1976.

Fuente: Juan Navarro Baldeweg.

\section{Concepto, pensamiento y forma (1990-2007 y un epílogo)}

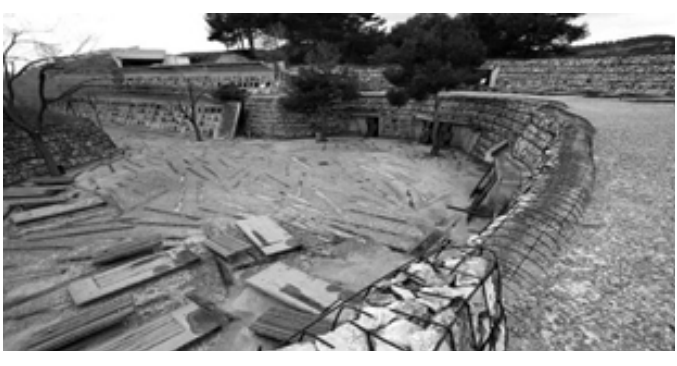

Figura 26: Enric Miralles. Cementerio de Igualada. Fuente:https://www.flickr.com/photos/leonl/630636305/ in/gallery-nicholasboyarsky-72157623159951994/

En 1990 la atención de la nueva generación estaba más centrada en la ondulante propuesta para el Cementerio de Igualada de Pinós y Miralles que en el pasado o en lo que llegaba de fuera. Se iniciaba así un periodo extraordinario de la arquitectura española, que pasa radicalmente del aislamiento y la observación, a ser actora principal y creadora de tendencia; de ser importadora, a participar activa y eficazmente en la corriente informativa global, exportando ideas y proyectos por la altísima capacidad que acompañó las últimas décadas. ${ }^{4}$

El nuevo posicionamiento, de nuevo abierto a lo extradisciplinar, situándose en un magma de arte, pensamiento y cultura, tanto como en el dominio de la técnica siempre vinculado a la mejor tradición de las Escuelas de Arquitectura, influye decididamente sobre el panorama creativo del presente, en el que en muchos casos es más obvia la relación con lo "común social" que con adscripciones a grupos transfronterizos.

Desde hace unos años- $y$ en aumento exponencial ahora - la comunicación, y no el viaje, es la que hace al mundo sobrevolado y transparente. El trabajo individual (y el

${ }^{4}$ Ver el texto Península sin perímetro de Luis Fernández-Galiano 
colectivo, como suma de individualidades) disuelve las adscripciones a tendencias o grupos preformados. La información fluye en todos los sentidos, sin fronteras ni anacrónicas construcciones culturales en regiones o países. La masa informativa es de tal calibre, que el flujo se convierte en marejada de corrientes culturales y episódicas olas, en las que, como mucho cabe, ya no se trata de navegar con rumbo fijo, sino surfear, saber deslizarse sobre ese mar agitado de la información, entre las corrientes de ese pensamiento fluido o líquido, como lo llama Baumann (y esto en todas las esferas, tanto en la arquitectura, como en los demás aspectos que afectan a la sociedad contemporánea, tal como se demuestra en la obstinada crisis última).

Se inaugura una época en que las formas están guiadas por elementos externos a la disciplina; en que el pensamiento construye el proyecto, tanto como el lugar o la contaminación con las artes; en que el proyecto es construcción de un ambiente más que de un objeto, y quiere ser como una sección de las tensiones del lugar (en esa bella descripción de Juan Navarro Baldeweg).

Pero también se trata de un momento terrible, en que la especulación inmobiliaria y el "nuevorriquismo" destroza más territorios y entornos por año que lo que antes se hacía en décadas. Todo ello hasta la crisis última, en que la arquitectura se renueva necesariamente, emergiendo de ella nuevos valores basados en la potenciación de lo sostenible, del reciclaje, de la acción débil..

\subsection{Vínculo entre pensamiento y acción}

El cambio, en los años noventa, vino en gran medida de la mano de nuevas ideas o pensamientos que se incorporaron al diálogo arquitectónico con la misma naturalidad que hasta entonces lo habían hecho las formas: la deconstrucción, las teorías de campo, lo isotrópico, lo difuso, el pensamiento ironista, transforma la base conceptual de la arquitectura, que trata de encontrar, por cualquier vía posible, la urgente conexión con la sociedad.

Los textos de Virilio, Derrida, Gilles Deleuze o Richard Rorty ejercen en España una influencia mayor quizás que los propios proyectos que se realizan en el exterior. El

\footnotetext{
${ }^{5}$ El diccionario Metápolis fue el resultado de dos encuentros celebrados en Barcelona en 2000 y del esfuerzo editorial de ACTAR y la capacidad motivadora y aglutinadora de Manuel Gausa. Participaron, entre otros, Vicente Guallart, Willy Müller, José Morales, Fernando Porras, Federico Soriano, Ábalos y Hereros, Pepe Ballesteros, Xavier Costa, Enric Ruiz-Geli, Alejandro Zaera o Magüi González y José Antonio Sosa entre otros. Significativamente relacionado con el concepto que sirvió de base al trabajo es la cita inicial del diccionario, de Albert Camus: "por qué soy un artista y no un filósofo? Porque pienso según las palabras y no según las ideas" (como se citó en Gausa, 2001)

${ }^{6}$ Vale la pena aún bajo la inevitable parcialidad, asumir el riesgo del directo al hablar de un periodo tan cercano. No se trata de ser objetivo en el texto; sería un esfuerzo baladí. Involuntariamente se reflejan ideas que pueden ser demasiado particulares o de un colectivo especifico; pero siempre tratando de evitar lo excluyente.
}

pensamiento se busca fuera, es casi todo importado; con honrosísimas excepciones, pero la reflexión se extiende, o mejor se expande, y se acaba por hacer colectiva. Las propuestas conceptuales de Ábalos (luego con Sentkiewicz) y Herreros, o las de Gausa con ACTAR y el resultado de METÁPOLIS son un buen ejemplo. ${ }^{5}$

La situación contemporánea, cambia tan rápido que las dos últimas décadas no pueden ser leídas de modo uniforme. La búsqueda voluntaria de vínculos con el pensamiento contemporáneo, siempre de diversos orígenes y procedencia, elevó la arquitectura española de finales de los noventa y dos mil a cotas importantes. La sociedad contemporánea es poco proclive a defender jerarquías y órdenes fijos ni cerrados. Esto llevó a la localización de nuevas formas de organización más abiertas, más próximas al concepto heideggeriano de armazón que al de idea, entendida como imagen fija, compuesta y preestablecida. ${ }^{6}$

Estas estructuras abiertas y no jerárquicas conducen a la localización de soluciones nuevas, abandonando razones tipológicas y ahondando en los recorridos como elementos organizadores (caso de Zaera en Yokohama), superficies continuas, pliegues, estructuras de campo, estructuras difusas... A la vez, se asiste a la recuperación- de nuevo- de conceptos abandonados en los sesenta, como las superposiciones, yuxtaposiciones y apilamientos, presentes entonces en la arquitectura de Moshe Safdie, Atelier 5, Paul Rudolph, que retornan como respuesta contingente a la misma búsqueda de estructuras no jerárquicas, pero que ahora son reconducidas por la construcción del lugar, un parámetro cada vez más importante y diferenciador. La necesidad de investigar y localizar modos de organización de los límites - los contornos, que hagan compatible la isotropía (y por lo tanto la teórica continuidad de la planta o la idea conceptual de una estructura organizativa llevada hasta el infinito) con la necesidad de contención y definición del borde, para no perder en el proceso la capacidad de construcción de un nuevo ambiente se convierte en un nuevo campo de creación en el que aún estamos inmersos hoy. ${ }^{7}$

\footnotetext{
7 En este contexto de hibridación de pensamiento y acción, destacar la incorporación de innumerables arquitectos españoles a una docencia relevante en prestigiosas universidades extranjeras, dirigiendo cátedras o departamentos, como por ejemplo, y sin ánimo de ser exhaustivo, las de Iñaki Ábalos en el GSD de Harvard (con el notable precedente de José Luis Sert y Rafael Moneo). O las de Juan Herreros en Columbia, Alejandro Zaera en el Instituto Berlage y Princeton, Beatriz Colomina también en Princeton, Manuel Gausa en Génova, Enric Miralles en Harvard, José Luis Mateo en la ETH y un largo etcétera de notable valía.
} 


\subsection{Un mundo transparente de información}

El presente se adivina nuevo. La última crisis (2008) se cebó justamente en la profesión. Como en otros tiempos, retornó la emigración de profesionales capaces de exportar los esfuerzos y las enseñanzas de nuestras Escuelas al exterior, aunque con el consuelo, o la esperanza, de un futuro retorno de la experiencia y el conocimiento adquiridos.

Pero esta migración no es solo de personas sino, de modo acelerado y desbordante, de información: los blogs, las páginas y las revistas digitales invaden las páginas de Instagram, Facebook y Twitter de luminosa información arquitectónica que, paradójicamente, siendo esta vez planetaria, es asombrosamente parecida entre sí. La competencia entre estas páginas digitales por contar con miles de "amigos y seguidores" Ileva a la exacerbación de la pauta (ya existente antes, aunque a otra escala) de publicar "lo que vende"; la imagen poderosa, luminosa, el flash de un momento, en una esfera informativa en que no se dedica más de unos segundos a revisar la obra o e proyecto. Si antes las revistas venían acompañadas, de una propuesta ideológica, de unas reglas de juego o de cierta pauta comprensible, ahora se trata de navegar ágil y limpio a través de un infinito bosque de información.

Esta nueva forma de conocer el mundo tiene la ventaja, de ser multifocal y rizomática. Alejada de enfoques lineales y direcciones únicas; antes, al contrario, es recíproca y se lanza en todas las direcciones. Por lo que intrínsecamente, y en teoría, debería ser capaz de evitar ser dirigida, controlada o incluso digerida, por un único sistema. Debería ser y ya no es, la esfera del individuo o de los colectivos (como agregación de individuos); debería ser, en términos sociales, de las minorías globales (Eugenio Trías), cada día más reales y eficaces. E presente es de las redes, de la comunicación global y de mundo transparente de información. Y en él no debería haber influencias (como cada vez parece más evidente), sino pura inmersión.

\section{Conclusión. Ida y vuelta: hacia la información acrítica y desbordante}

La influencia mutua, entre la arquitectura moderna española y la producida en el exterior no siempre siguió el mismo patrón y sentido. Arrancó, durante el periodo heroico, mirando netamente hacia afuera y termina, en e último cuarto del siglo XX, con proyectos bien enlazados con el pensamiento contemporáneo y capaces, gracias a ello, de transmitirse ampliamente al exterior. Este cambio, acentuado en España por el tránsito de la autarquía a la democracia, convierte a la arquitectura española en exportadora de formas e ideas.

En años más recientes, con la expansión, cada vez más acelerada, del fenómeno de la globalización y del intercambio masivo de información, desaparece la focalidad, y con ello, la idea de influencia se hace banal.

De lo difuso, y a veces nublado, de la información emergen sucesivamente y sin aparente vinculación entre sí, nuevas formas y tendencias. Incluso es muy posible que el bombardeo de imágenes elimine algún tipo de pensamiento común. Puede que, con el tiempo, se descubra en ellas, algo más que la relación netamente visual con la que nos agobia (con la inestimable colaboración de la IA) Pinterest o Instagram. Vivimos aún demasiado cerca de esa atractiva pero vacía nebulosa de imágenes para poder sacar alguna conclusión definitiva; si es que debe haberla, porque también puede que sea precisamente esa incertidumbre, la que gobierne la arquitectura en adelante.
${ }^{8}$ Es significativo que Rem Koolhaas, buen sismógrafo y siempre oportuno, en su propuesta para la Bienal Venecia de 2014 sostuviera: "Bajo la presión de guerras, regímenes políticos muy diferentes, múltiples condiciones de desarrollo, movimientos arquitectónicos, talentos individuales, amistades, desarrollos tecnológicos, las arquitecturas que antes eran específicas y locales ahora son intercambiables y globales". (Fernández, 2013). 


\section{Referencias bibliográficas}

\author{
- Alexander, C. (1965). A City is Not a Tree. Architectural
} Forum. 122(1), 58-62.

- Bru, E. y Mateo, J.L. (1990). Arquitectura española contemporánea. Barcelona, España: Gustavo Gili.

- Capitel, A. (1995) Arquitectura española 1939-1992. Arquitectura española del siglo XX, Summa Artis, 40, 357-630.

- Cortés, J.A. (1995). Releyendo la Historia: La Arquitectura del Racionalismo Madrileño. 3ZU: revista d'arquitectura, (4) $14-19$.

- Cortés, J.A. (2001). Internacionalismo y referencias vernáculas en los años cincuenta. En Arquitectura del siglo XX: España. Madrid, España: Tanais.

- Domenech, L. (1968). Arquitectura española contemporánea. Barcelona, España: Blume.

- Fernández, M. (2013). Rem Koolhaas contra las estrellas. El País. Madrid: Grupo Prisa. Recuperado de https://elpais.com/cultura/2013/01/27/ actualidad/1359314306_094188.html

- Fernández-Galiano, L. (1998). Península sin perímetro. En A. Capitel, Arquitectura española del siglo XX. Historia del Arte. Madrid, España: Espasa Calpe.

- Fernández-Galiano, L. (2000). Península sin perímetro; la obra de arquitectos extranjeros en España y de españoles fuera del país. En Arquitectura del siglo XX España. Madrid, España: Tanais.

- Flores, C. (1961). Arquitectura española contemporánea. Bilbao, España: Aguilar.

- Gausa, M., Guallart, V., Müller, W., Soriano, F., Morales, J. y Porras, F. (2002). Diccionario Metápolis de Arquitectura Avanzada. Barcelona, España: Actar.

- Güell, X. (1984). Arquitectura española contemporánea. La década de los 80. Barcelona, España: Gustavo Gili.

- Martín-Hernández, M. (1987). Desde la hemeroteca de Miguel Martín-Fernández. En El Cabildo Insular y la Ciudad Racionalista. (Edición al cuidado de José Luis Gago). Las Palmas, España: Ed. Cabildo Insular de Gran Canaria.

- Paz, O. (1966). Prólogo. En Poesía en movimiento, México 1915-1966. México D.F., México: Siglo XXI editores.

- Pozo, J.M. y García-Diego, H. (2010). Viajes en la transición de la arquitectura española hacia la modernidad. Pamplona, España: Escuela Técnica: Ediciones Universidad de Navarra. EUNSA.
- Ramos, C. (2010). Construyendo la Modernidad, Escritura y Arquitectura en el Madrid Moderno 1918-37. Lleida, España: Ediciones de la Universidad de Lleida.

- Rossi, A. (1971). Arquitectura de la Ciudad. Barcelona, España: Gustavo Gili.

- Ruíz Cabrero, G. (2001). El Moderno en España. Madrid España: Tanais.

- Sambricio, C. (1998). Desarrollo del Gran Madrid. En A Capitel, Arquitectura española del siglo XX. Historia del Arte. Madrid, España: Espasa Calpe.

- San Antonio Gómez, C. de (2006). La influencia americana en la arquitectura Hospitalaria en la España de los años Treinta. En La arquitectura norteamericana, motor y espejo de la arquitectura española en el arranque de la modernidad (1940-1965). Congreso llevado a cabo en nombre de ETSA de la Universidad de Navarra, Navarra, España.

- Sola Morales, I. (1995). Topografía de la arquitectura contemporánea. Barcelona, España: Editorial Gustavo Gili.

- Sosa Díaz-Saavedra, J. A. (2002). La Casa del Marino, las Palmas de Gran Canaria, 1958-1964 Miguel MartinFernández. Almería, España: Colegio de Arquitectos de Almería.

- Sosa Díaz- Saavedra, J. A. (2002). Arquitectura Moderna en Canarias: 1925-1965. Tenerife, España: Colegio Oficial de Arquitectos de Canarias.

- Venturi, R. (1977). Complexity and Contradiction in Architecture. New York, Estados Unidos: The Museum of Modern Art

- VV AA. (1996). Arquitectura del Movimiento Moderno 1925-1965. Barcelona, España: Fundación Mies van der Rohe/ Registro DOCOMOMO Ibérico.

- VV AA. (2000). Arquitectura del siglo XX: España. Madrid, España: Sociedad Estatal Hannover y Tanais.

- VV. AA. (2005). AC-Publicación del GATEPAC. Barcelona, España: Fundación Caja de Arquitectos. 